\title{
Knockout of MDA-9/Syntenin (SDCBP) expression in the microenvironment dampens tumor-supporting inflammation and inhibits melanoma metastasis
}

\author{
Swadesh K. Das ${ }^{1,2,3}$, Chunqing Guo ${ }^{1}$, Anjan K. Pradhan ${ }^{1}$, Praveen Bhoopathi ${ }^{1}$, \\ Sarmistha Talukdar ${ }^{1}$, Xue-Ning Shen ${ }^{1}$, Luni Emdad ${ }^{1,2,3}$, Mark A. Subler ${ }^{1}$, Jolene J. \\ Windle $^{1,2,3}$, Devanand Sarkar ${ }^{1,2,3}$, Xiang-Yang Wang ${ }^{1,2,3}$ and Paul B. Fisher ${ }^{1,2,3}$ \\ ${ }^{1}$ Department of Human and Molecular Genetics, Virginia Commonwealth University, School of Medicine, Richmond, VA, USA \\ ${ }^{2}$ VCU Institute of Molecular Medicine, Virginia Commonwealth University, School of Medicine, Richmond, VA, USA \\ ${ }^{3}$ VCU Massey Cancer Center, Virginia Commonwealth University, School of Medicine, Richmond, VA, USA \\ Correspondence to: Swadesh K. Das, email: swadesh.das@vcuhealth.org \\ Paul B. Fisher, email: paul.fisher@vcuhealth.org \\ Keywords: melanoma differentiation associated gene-9/syntenin (mda-9/syntenin), syndecan binding protein (SDCBP), tumor mi- \\ croenvironment, myeloid-derived tumor suppressor cells (MDSC), interleukin -17A (IL-17A) \\ Received: March 09, $2016 \quad$ Accepted: May 25, $2016 \quad$ Published: June 21, 2016
}

\section{ABSTRACT}

Cancer development and progression to metastasis is a complex process, which largely depends on bidirectional communication between tumor cells and their microenvironment. Melanoma differentiation associated gene-9 (mda-9, also known as Syntenin-1, SDCBP), a gene first cloned by our group, is robustly expressed in multiple cancers including melanoma and contributes to invasion and metastasis in a tumor cell-intrinsic manner. However, the role of MDA-9/Syntenin in the tumor cell-extrinsic microenvironment remains unclear even though MDA-9/Syntenin is ubiquitously expressed in most organs that are active metastatic sites for melanoma, e.g., lung, lymph node, brain, and liver. In this study, we explored the effect of mda9/syntenin expression in the microenvironment on melanoma growth and metastasis using multiple immunocompetent animal models, syngeneic B16 xenograft and intravenous B16 mouse model and a genetically engineered mouse (GEM) model of melanoma. Host-deficient expression of $\mathbf{m d a - 9 / s y n t e n i n ~ i n ~ m i c e ~ n e g a t i v e l y ~ i m p a c t e d ~}$ on subcutaneously implanted B16 tumor growth and lung metastasis. Absence of MDA9/Syntenin in the lung microenvironment suppressed tumor growth by modulating in situ Interleukin 17A (IL-17A) expression and impaired the recruitment of myeloid derived suppressor cells (MDSCs) and Th17 cells as compared to genetically wild type animals. Additionally, loss of $\mathbf{m d a}-\mathbf{9} /$ syntenin expression in a spontaneous melanoma model (melanocyte-specific pten loss and Brafv600E mutation) significantly delayed tumor initiation and suppressed metastasis to the lymph nodes and lungs. The present study highlights a novel role of $\mathbf{m d a - 9 / s y n t e n i n ~ i n ~ t u m o r - p r o m o t i n g ~ i n f l a m m a t i o n ~}$ and immune suppression. These observations along with other documented roles of MDA-9/Syntenin in cancer and metastasis support the potential relevance of MDA$9 /$ Syntenin in the carcinogenic process and as a target for developing improved therapies by using either genetic or pharmacologic approaches to treat and prevent melanoma and other cancers. 


\section{INTRODUCTION}

Metastasis is a multifaceted process that initiates with the migration of tumor cells from a primary site and culminates in the formation of new secondary tumors in distant organs [1]. For successful survival and growth of metastatic cells in their new environment, disruption of homeostasis of the host organ is crucial [2]. Each organ contains multiple cell types organized in an ordered/structured architecture and numerous molecular/ biochemical processes are necessary to maintain physiological functions [1]. Through mechanisms that require further clarification, specific biochemical and molecular changes, either induced by invading cancer cells or occurring as spontaneous events, can disrupt this organization and facilitate tumor cell colonization and growth [3]. Numerous studies support the importance of cross talk between the resident cells (in target organs) and invading cells in mediating metastasis [3]. In principle, the homing organ can serve as a 'perfect ecosystem' that can provide nutritional support and protection from the immune system to facilitate tumor growth.

Syndecan binding protein (SDCBP), mda-9/syntenin [4-6], a temporally expressed gene was initially cloned from terminally differentiating human melanoma cells as mda-9/syntenin in 1993 and described in detail in 1996 $[4,5]$. Subsequently, our primary research emphasis has been to define the role of $m d a-9 /$ syntenin in cellular transformation and metastasis. We provided definitive evidence that $m d a-9 /$ syntenin is a pro-metastatic gene when expressed in immortal normal human cells and in human cancer cells of diverse origin with an ability to induce invasion and experimental metastasis [7-11]. The diverse roles of mda-9/syntenin (SDCBP) in exosome biogenesis [12-16], intracellular trafficking [17, 18], neuronal differentiation [19-21], immune cell migration [22-25] and anti-viral activity [26, 27] are also current areas of intense investigation in multiple laboratories. In total, these studies validate the functional importance of MDA-9/Syntenin in maintaining both normal cellular physiology and promoting cancer progression. Recently, Tamura et al. reported that mda-9 (syntenin-1) knockout mice exhibit abnormalities in immunoglobulin production and have a modified intestinal microbiota [28]. Current studies support the hypothesis that mda-9/syntenin is involved in multiple signaling cascades under both physiological and pathological conditions and these processes affect various phenotypes in a tissue/organ context-dependent manner. However, the physiological role of MDA-9/Syntenin (SDCBP) in the target organ niche remains to be explored. At present, we have a clearer appreciation of how MDA-9/Syntenin facilitates tumor cell invasion from a primary tumor site [7-11], i.e., how this protein regulates autonomous and non-autonomous signaling of tumor cells to degrade the extracellular matrix (ECM) [7-9, 29-32], promotes migration [29-
$31,33]$, induces angiogenesis [11, 33] and facilitates escape from the primary tumor niche. Since the MDA9/Syntenin protein is also expressed in multiple organs under physiological conditions, it is relevant to define the precise role of basal expression of this protein, if any, in the context of the host organ microenvironment, which is a critical regulator of metastasis.

Accumulating evidence suggests that a local immune-suppressive and inflammatory microenvironment is a key element for tumor progression and invasion [34-36]. Myeloid derived suppressor cells (MDSCs), a heterogeneous population of cells of myeloid origin, have garnered attention due to their immune suppressive functions in a tumor bearing host [37-39]. These effects are elicited by suppressing effector T cells [37], converting naïve $\mathrm{CD}^{+} \mathrm{T}$ cells to regulatory $\mathrm{T}$ cells (Tregs) [40] and inhibiting $\mathrm{T}$ cell trafficking [41]. $\mathrm{CD} 4^{+} \mathrm{Th} 17$, a subset of $\mathrm{CD}^{+} \mathrm{T}$ cells, is an additional type of immune suppressive cell that also infiltrates tumors and correlates with tumor progression [42]. Interleukin 17A (IL-17A), a pro-inflammatory cytokine secreted by $\mathrm{CD}^{+} \mathrm{Th} 17$ cells, triggers tumor cells to produce interleukin 6 (IL-6), which in turn activates STAT3-dependent survival and angiogenesis [43]. Additionally, IL-17 production in the tumor microenvironment promotes infiltration of MDSCs to promote immune suppression and to amplify tumorpromoting inflammation [44]. The behavior of cancer cells is influenced to a great extent by various cytokines produced by resident immune or non-immune cells in the tumor microenvironment in response to invading tumor cells. In this study, we show that lack of $m d a-9 /$ syntenin expression in the host lung influences the local inflammatory network, indicated by the reduced level of pro-inflammatory cytokines such as IL-6 and IL-17A, as well as diminished accumulation of Th17 cells and MDSCs. This defect in tumor-supporting inflammation strongly suppresses tumor progression as evidenced by a delay and reduction in metastatic melanoma development.

\section{RESULTS}

\section{Phenotype of mda-9/syntenin knockout (mda-9--) mice}

As reported previously by Tamura et al. [28] using syntenin-1-deficient mice, we did not observe any phenotypic differences (Supplementary Figure S1), embryonic lethality, developmental abnormalities, or adult sterility in our $m d a-9^{-/}$mice. Additionally, body weight changes up-to six months and various organ weights at 3 months were similar between $m d a-9^{-/}$and wild type (WT) C57BL/6 mice (data not shown). We confirmed in our $m d a-9-\triangleleft$ mice the absence of MDA-9/Syntenin protein in multiple tissues (lung shown) from mice homozygous 
for the knockout ( $m d a-9^{-/-)}$allele as well as the original "knockout first" ( $m d a-9^{-/-}$neo) allele (Figure 1A).

\section{mda-9-deficient mice are less supportive for murine B16-derived xenograft tumor growth}

Our previous studies firmly established the relationship between mda-9/syntenin expression and melanoma metastasis [8, 45]. In the present study, we evaluated mda-9/syntenin as a host factor and defined whether host expression could influence tumor growth when B16 cells were implanted subcutaneously in mda-9-/ mice and their WT littermates (C57BL/6). B16 cells abundantly express MDA-9/syntenin (data not shown, [46]. Overall, B16 cells grew faster in WT mice compared with $m d a-9^{-/-}$mice. During the time course of the experiment (from day 3 to day 24) delayed tumor growth was observed in the $m d a-9^{-/-} v s$. mda-9 WT mice (Figure 1B). The tumor volumes from WT mice were 2 fold greater than tumor volumes from $m d a-9^{-/-}$mice at day 15 post-inoculation. By day 18 and 24, 2.5-fold greater tumor volumes were found in WT mice as compared to $\mathrm{mda}^{-9^{-/}}$mice. The average tumor weight was $\sim 40 \%$ less in the $m d a-9^{-/}$group than in the WT group (Figure 1C). In total, these results suggest that mda-9/syntenin deficiency in the microenvironment negatively impacted tumor (melanoma) growth. H \& E sections from WT mice indicated substantial pigmented cells in tumors, which were less apparent in the $m d a-9^{-/}$group (Figure 1D).

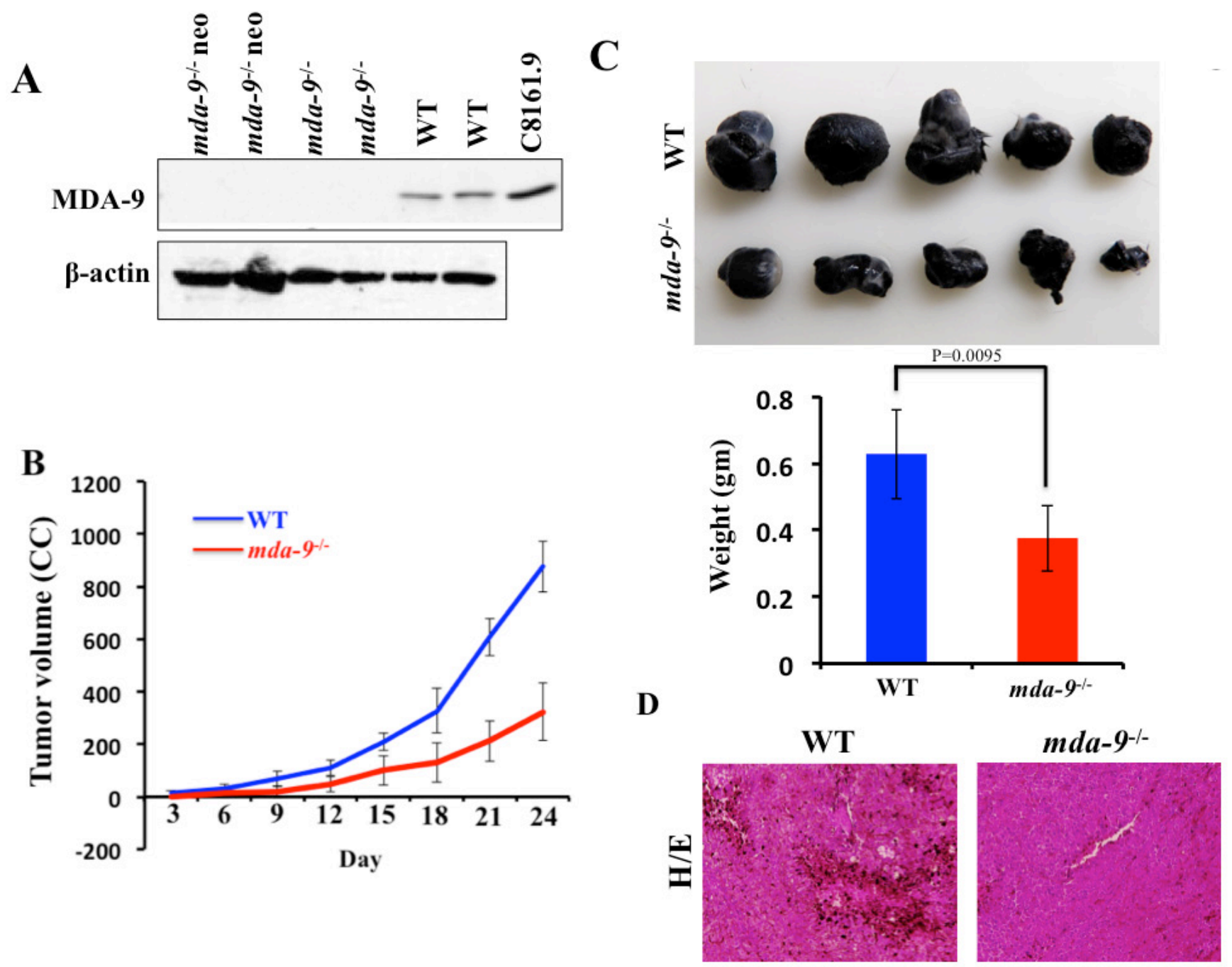

Figure 1: B16 xenograft tumor growth is suppressed in mda-9/syntenin-deficient mice. A. MDA-9/Syntenin expression in the lungs of $m d a-9 \mathrm{KO}\left(m d a-9^{--}\right)$animals. Western blot analysis of MDA-9/Syntenin expression in lung tissue from mice homozygous for the floxed allele (CKO), the "knockout first" allele (KO neo), the final knockout allele (KO) or the wild type allele. $\beta$-actin was used as loading control. B. Growth kinetics of B16 xenograft tumors in experimental animals (WT and $m d a-9^{-/}$). Tumor volumes were calculated on every $3^{\text {rd }}$ day based on the calculations described in Methods and Materials. Average volumes from five mice are presented \pm S.D. C. Photographs of tumors at the end of this study ( 24 days after injection). Average weight of tumors from each experimental group is presented. Data represents value from 5 mice with \pm S.D. D. Representative photograph of hematoxylin/eosin-stained tumor sections. 


\section{mda-9/syntenin deficiency in the lungs of mice modulates B16 lung nodule growth}

The lungs are the most common site for melanoma metastases [47]. Injection of B16 cells through the lateral tail vein results in pulmonary metastasis in C57BL/6 animals. To define a potential impact of mda-9/syntenin deficiency in the host lung on the development of metastatic nodules, B16 cells were injected into the tail vein of $m d a-9^{-/-}$and WT mice. Lung metastases were evaluated by gross morphology of the lungs (Figure 2A), determining the number of metastatic nodules on the lung surface (Figure 2B), and lung morphology (presence of tumor and lung structure) (Figure 2C) on days 15 and 21 [48]. Overall, the WT group manifested enhanced pathology compared with $m d a-9^{-/-}$mice, as indicated by an increased number of pigmented melanoma nodules in the lungs at each time point (Figure 2A). Visible lung nodules were first apparent between day 3 to day 6 after B16 injection in WT mice, while nodules only became apparent at day 6 in the $m d a-9^{-/-}$mice, and dramatically

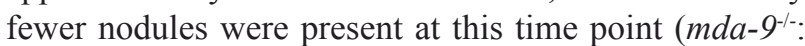
$0.33 \pm 0.57$ vs. WT: $9.33 \pm 5.5$ ). Similarly, at later time points (day 9, 15 and 21) the difference in lung nodule numbers was also significantly different between these two groups (Figure 2A and 2B). Additionally, the size of nodules was comparatively larger at all later time points (day 15 and 21, Figure 2C) in WT mice.

In a second experiment, mda-9/syntenin expression was downregulated in B16 cells using shRNA for $m d a-9 /$ syntenin ( $\operatorname{sh} m d a-9$ ), and these and control cells (shcon) were injected via tail vein into both WT and $m d a-9^{-1-}$ mice. After 6 days, mice were sacrificed and nodules
$\mathbf{A}$

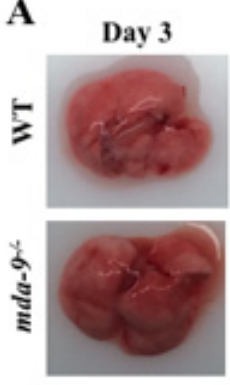

C

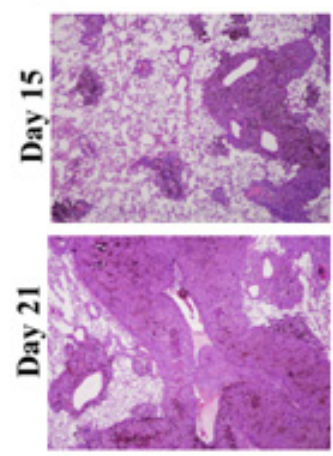

WT
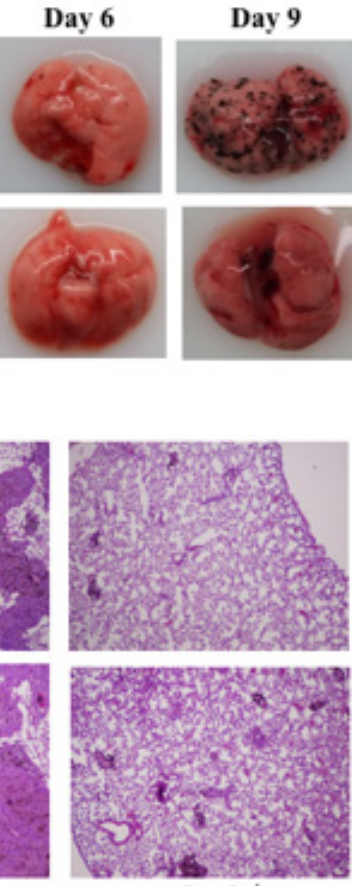

mda-9--

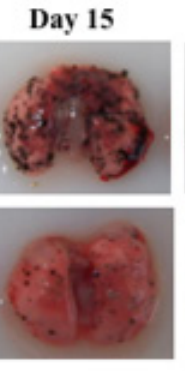

D

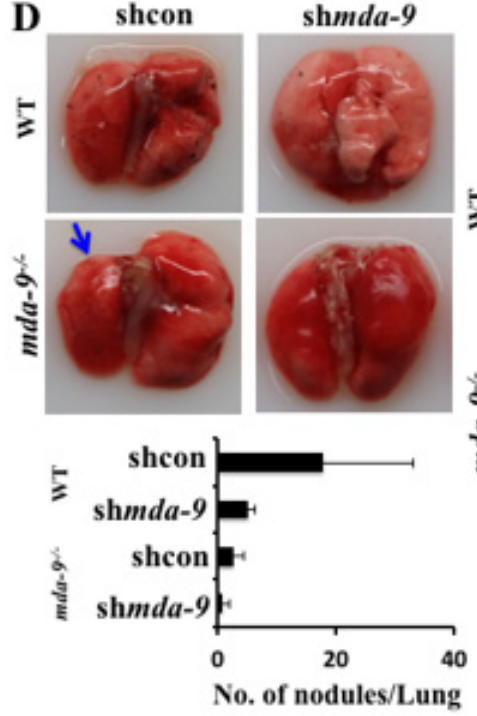

B

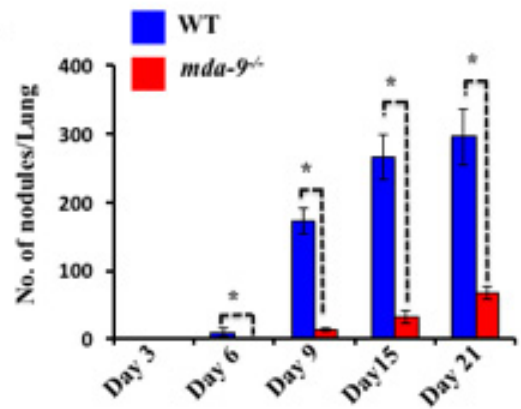

E
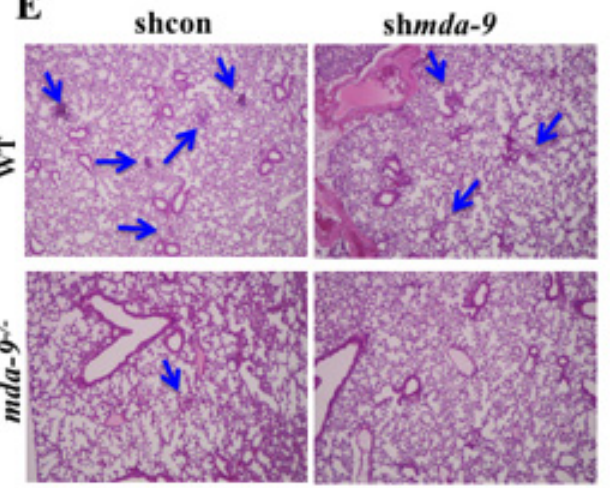

Figure 2: Lung metastasis development is inhibited in mice lacking mda-9/syntenin. A. Formation of metastatic nodules in the lungs of WT and $m d a-9^{-/}$mice. A cohort of 15- age (6 weeks) and sex (male) matched wild type (C57BL/6) and $m d a-9^{-/}$mice were inoculated with B16 cells $\left(1 \mathrm{X} 10^{5}\right)$ by intravenous injection to generate experimental lung metastases. Every $3^{\text {rd }}$ day, 3 mice from each group were sacrificed and lungs were collected, fixed with formalin and examined for nodules. Representative photographs of lungs with tumor metastases are presented. B. Graphical representation of average surface nodule number/mouse from each time point is presented. C. Photomicrographs of gross hematoxylin/eosin-stained lung sections are shown. D. In a separate study, a cohort of 6 animals from each mouse type (WT and $m d a-9^{-}$) was inoculated with shcon or shmda-9 transfected B16 cells through tail-vein injection. After 6 days, lungs from each group were analyzed for lung nodule development. Representative photographs and the average number of nodules/mouse from each experimental group are shown in the upper and lower panel, respectively. E. Representative photomicrographs of gross lung hematoxylin/eosin stained lung sections are shown. 
were counted. As predicted, silencing of mda-9/syntenin in B16 cells significantly reduced their ability to form tumor nodules in WT mice (Figure 2D, WT: shcon vs. shmda-9 panel). As observed in our initial experiments using unmodified B16 cells (Figure 2A), fewer nodules were apparent in $m d a-9^{-/-}$mice injected with B16 shcon (Figure 2D, shcon WT vs. shcon $m d a-9^{-/-}$panel). In direct support of a role of mda-9/syntenin expression in the microenvironment impacting on tumor development, we did not observe any visible nodules in the $m d a-9^{-/-}$mice that received mda-9/syntenin knockdown B16 (shmda-9) cells (Figure 2D and 2E).
Inflammatory and immunosuppressive cells are reduced in the lungs of $\mathrm{mda}_{-} 9^{-/-}$mice

Since we observed a lower number of metastatic nodules in the lungs of $m d a-9^{-/-}$mice as compared with their WT counterparts (Figure 2), we hypothesized that mda-9/syntenin expression in the tumor microenvironment might result in an alteration in tumor-supporting inflammation in mda-9/syntenin-deficient mice. To test this assumption, we first analyzed the expansion of MDSCs in the lungs of tumor-bearing WT and $m d a-9^{-/-}$ mice using flow cytometry. Following the establishment of metastatic B16 tumors, lungs from WT mice contained significantly higher numbers of both monocytic MDSCs (M-MDSCs, CD11b ${ }^{+}$Ly6C ${ }^{\text {high }}$ Ly6G') and granulocytic

A
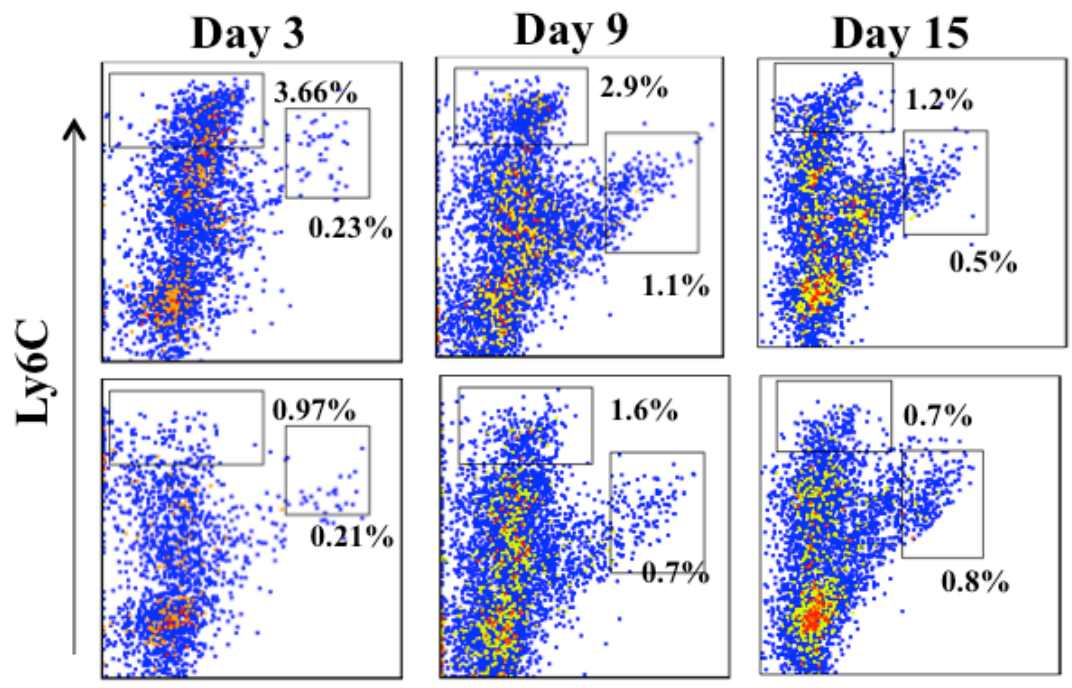

B

Ly6G

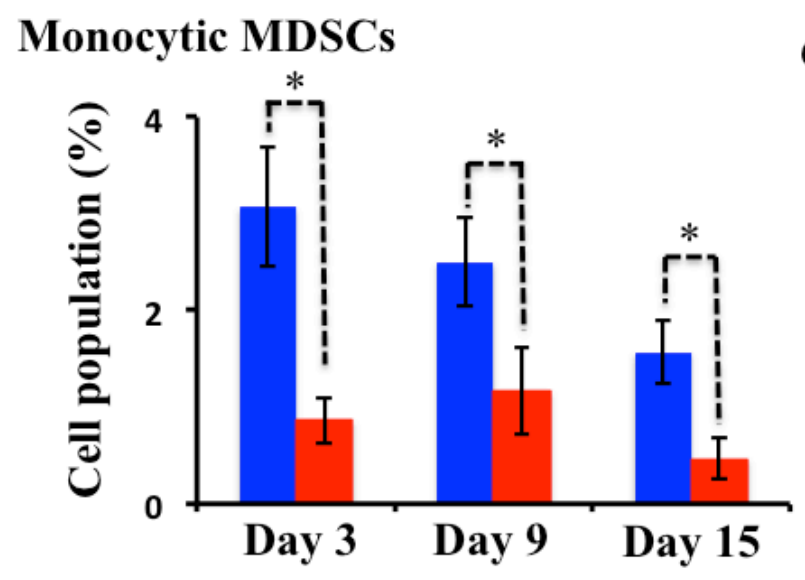

Granulocytic MDSCs

WT

mda-9-/

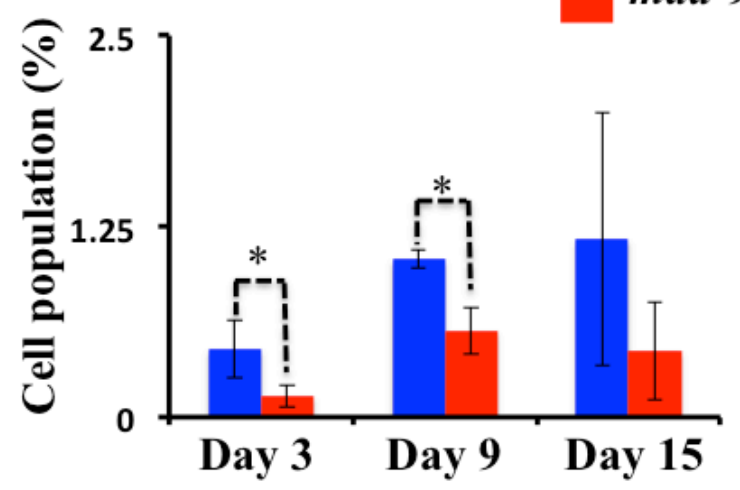

Figure 3: Infiltration of MDSCs is diminished in $\mathbf{m d a - 9} \mathbf{9}^{-/}$mice. A. Accumulation of MDSCs in tumor bearing mice. A cohort of 12 animals from each experimental group received B16 cells ( 1 X $10^{5}$ cells/mouse) through intravenous injection. Three mice from each group at different time points were sacrificed, single-cell suspensions of tumor bearing lungs were prepared and analyzed for MDSCs accumulation by flow cytometry (experimental protocol provided in Methods and Materials). Representative histograms from each group are presented. B. Graphical presentation of average monocytic and granulocytic MDSCs (\% of cells in the total population) from three animals at each time point \pm S.D. 
MDSCs (G-MDSCs, CD11b+Ly6C ${ }^{\text {low }} \mathrm{Ly}^{+} \mathrm{G}^{+}$) than those from $m d a-9^{-/}$mice (Figure $3 \mathrm{~A}$ and $3 \mathrm{~B}$ ). The differences were significant for M-MDSCs, a prominent subtype for melanoma [49], at all time points analyzed in this study (day 3, 9 and 15). It is worth noting that at day 21, the accumulation of MDSCs (both subtypes) in $m d a-9^{-1-}$ mice were not significantly different from the wild type (Supplementary Figure S2). It is possible that the lack of $m d a-9$ expression in the microenvironment has a more significant impact on host-mediated anti-tumor activity at early stage of tumor progression and over time the tumor cells in the niche overcome the immune suppression and their growth is expanded. Consistent with this hypothesis, we observed nodule sizes (representing increased tumor cell number) were dramatically larger on day 21 compared with day 15 (Figure 2A) in $m d a-9^{-/}$mice.

Interestingly, we observed several pro-inflammatory cytokines such as $I L-17 A, I L-6$ and $T N F-\alpha$ that were downregulated (at an mRNA level) in mda-9-deficient naïve lungs, suggesting a potential impairment of protumorigenic responses to invading tumor cells ( Figure 4A). To determine the consequences of absence of $m d a-9$ in the lungs of mice, we next examined the infiltration of $\mathrm{CD}^{+} \mathrm{Th} 17$ populations in the lungs of WT and $m d a-9^{-/-}$ mice in response to intravenous injected B16 cells. Flow cytometry analysis revealed lower numbers of $\mathrm{CD}^{+}{ }^{+} \mathrm{Th} 17$ cells in the lung tumors from $m d a-9^{-/-}$mice as compared to WT mice only at days 9 and 15 (total accumulation was gradually decreases as tumor progression occurred in both groups). Again, consistent with the MDSCs data presented in Supplementary Figure S2, CD4 ${ }^{+}$Th17 populations at day 21 were similar between WT and mda$9^{-/-}$mice. To evaluate potential changes in the expression of the pro-inflammatory cytokine IL-17A in response to B16 cell colonization, qPCR was performed with RNA isolated from mouse lungs. At day 3, lower levels of IL-
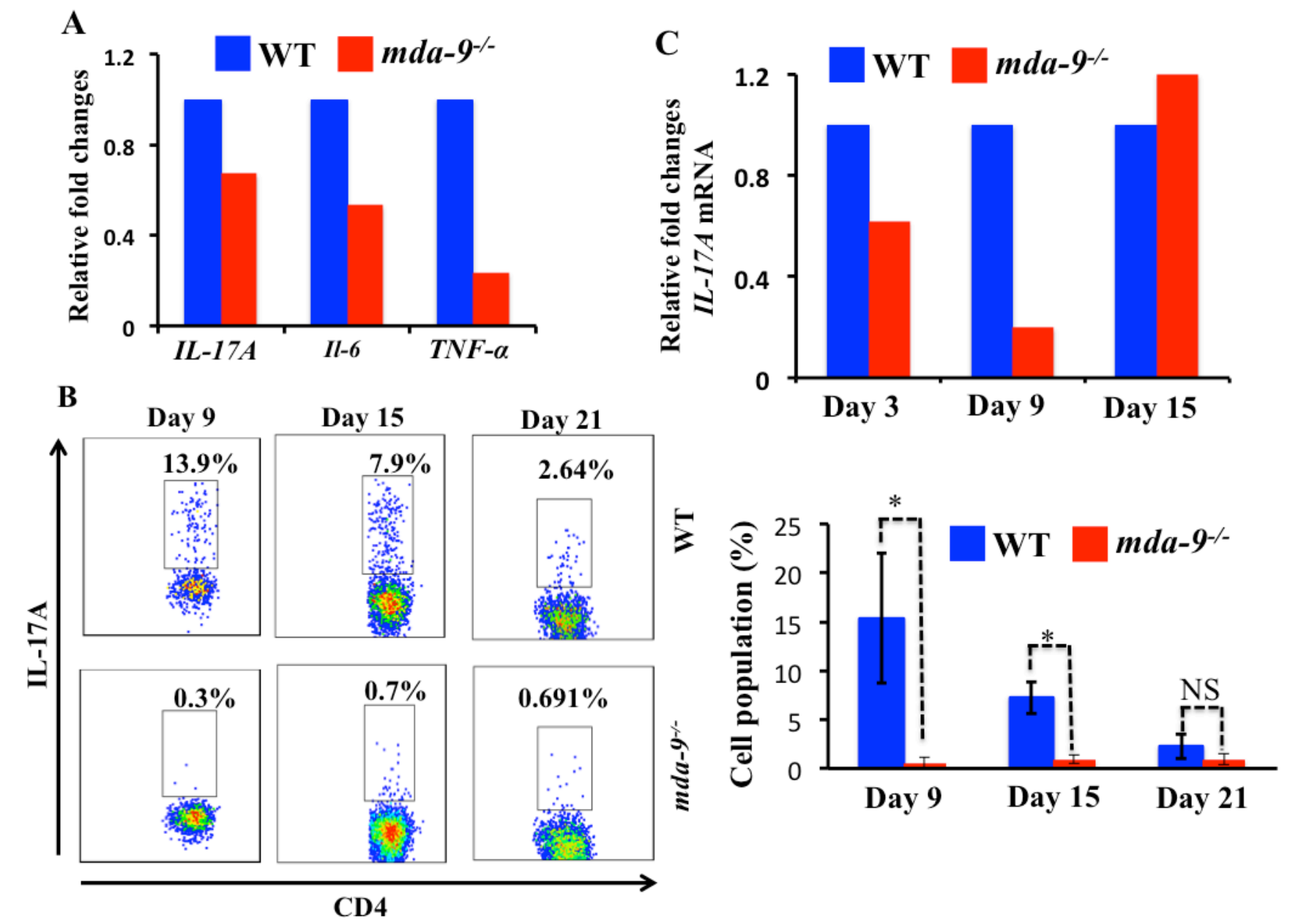

Figure 4: Knockout of mda-9/syntenin results in reduced $I L-17 A$ transcript expression and Th17 cell accumulation. A. Real-time PCR was performed to determine the different cytokines $(I L-17 A, I L-6$ and $T N F-\alpha)$ at mRNA level in naive lungs, isolated from age- (8-weeks) and sex- (male) matched WT and mda-9-/- mice. Values were normalized with endogenous mouse GAPDH. B. Infiltration of $\mathrm{CD}^{+} \mathrm{Th} 17$ cells in tumor bearing mice. A portion of lung cells from the experiment shown in Figure 3 was stained to identify IL-17A producing CD4 cells (CD4 ${ }^{+}$Th17) cells. Representative histograms and average value are presented in the upper and lower panels, respectively. C. mRNA expression level for $I L-17 A$ in tumor bearing lung tissue isolated from tumor bearing mice at different time points (day 3, 9 and 15). 
17A mRNA were evident in $m d a-9^{-/}$mice which was comparable to that of the naïve lungs (compare Figure 4A vs Figure 4C). At this time point, we did not find any difference in $\mathrm{CD}^{+}$Th17 cells (data not shown). A significant downregulation of $I L-17 \mathrm{~A}$ mRNA (Figure 4C) correlated with the $\mathrm{CD}^{+}$Th17 cells at day 9 (Figure 4B and Figure 4C). However, at day 15, we did not observe any differences of $I L-17 A$ mRNA in $m d a-9^{-/}$and WT groups. We did not explore the molecular mechanism in detail, but it is possible that other resident cells of the tumor microenvironment such as macrophages or T cells might produce IL-17A as a consequence of the presence of localized tumor cells. Overexpression of IL-17A might then facilitate the suppression of the host-mediated immune surveillance and allow the tumor cells to grow in $m d a-9^{-/}$mice, as evident in day 15 or later time points (Figure 2B). Further systematic studies are required to explore these phenomena, which are currently a focus in our laboratory.

\section{Deletion of mda-9/syntenin in BRaf ${ }^{V 600 E} /$ Pten $^{f / f l} /$ $T y r-c r e^{E R 2}$ mice delays tumor onset and inhibits formation of distant metastases}

In the BRaf $f^{V 600 E} /$ Pten $^{f l f l} / T y r-c r e^{E R 2}$ mouse model, tamoxifen-mediated activation of cre results in activation of expression of the Braf oncogene and knockout of the
Pten tumor suppressor gene specifically in melanocytes [50]. In the absence of tamoxifen, most of these mice display no discernible phenotype. However, topical or systemic administration of 4-hydroxytamoxifen (4HT) results in the rapid development of melanomas that recapitulate the key pathophysiological features of human melanoma, including metastases in lymph nodes and lungs, with animals requiring euthanasia within 3-6 weeks. To comprehend the role of $m d a-9 /$ syntenin in melanoma progression, we crossed $m d a-9^{-/-}$mice with the $B R a f^{V 600 E /}$ Pten $^{f l f t} / T y r-c r e^{E R 2}$ animals to develop mice that lack MDA-9/Syntenin expression. Systemic administration of 4-hydroxytamoxifen (4-HT) to parental BRaf ${ }^{V 600 E} /$ Pten $^{\text {flfl } /}$ Tyr-cre ${ }^{E R 2}$ mice induced pigmented lesions within 7 to 10 days (Figure 5A). However, deletion of mda-9/syntenin

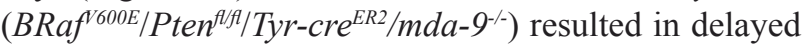
tumor formation (Figure 5A). Additionally, we also observed less metastasis to regional lymph nodes and lungs in BRaf $f^{V 600 E} /$ Pten $^{f l f l} / T y r-c r e^{E R 2} / m d a-9^{-/-}$(Figure 5B), which were assessed pathologically (presence of pigmented cells or lung morphology). These results provide further documentation of the role of mda-9/syntenin expression in the microenvironment in regulating primary tumor and metastasis formation in an autochthonous transgenic mouse model of melanoma containing an intact immune system.
A

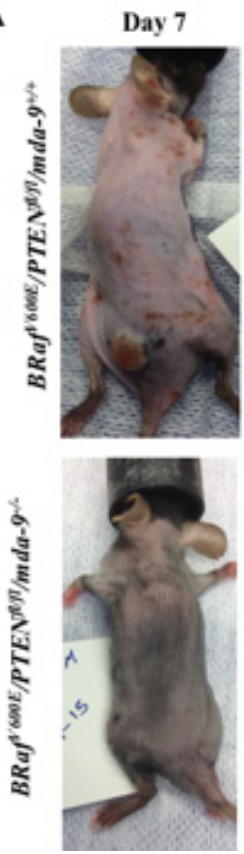

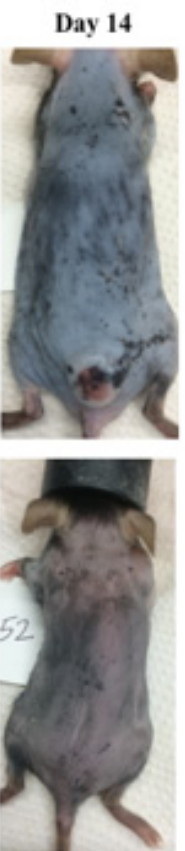

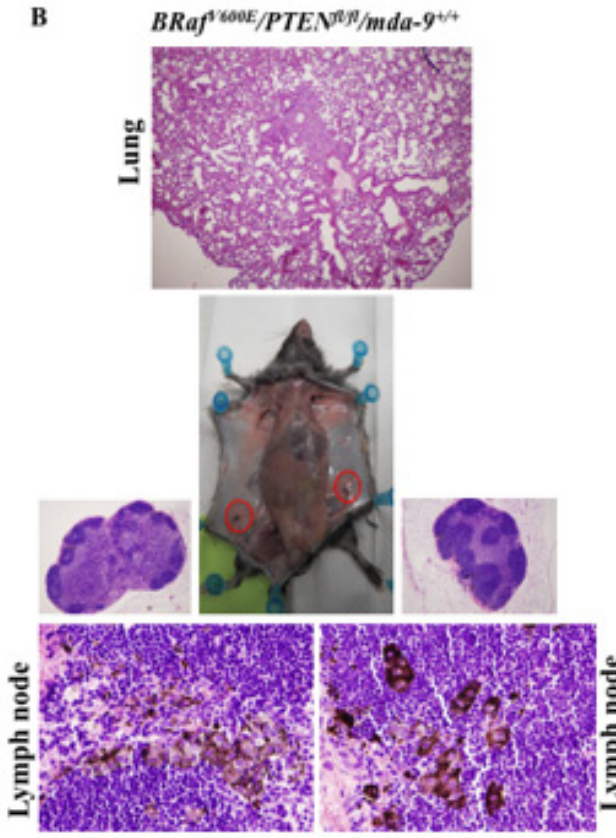

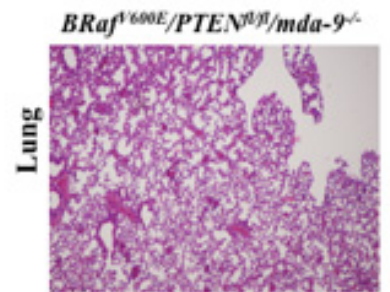

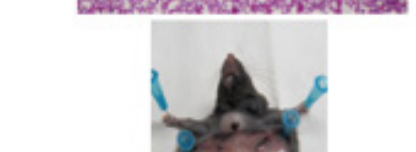

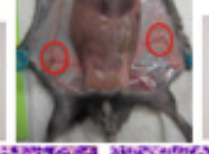
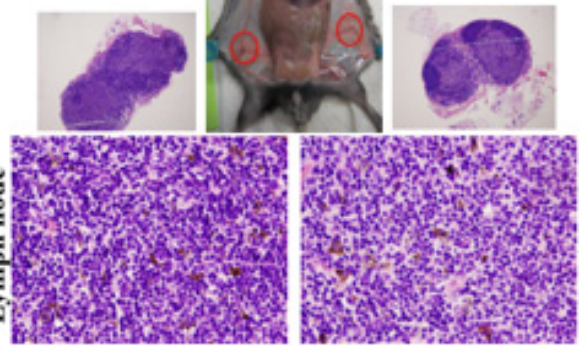

Figure 5: Lack of mda-9/syntenin delays tumor progression and lymph node and lung metastasis development in a transgenic mouse model of melanoma. A. Comparison of $B R a f^{V 600 E} / P T E N^{f f f} / m_{d a-} 9^{+/+}$(Upper panel) and $B R a f^{1600 E} / P T E N^{f f f} / m_{d a-} 9^{-/-}$ (Lower panel) tumor progression in the early stage of tumor induction by tamoxifen (7 and 14 days after 4-HT induction). B. Metastasis to lung and inguinal lymph nodes (black color) is shown at 28 days after 4-HT injection. Representative H \& E stained lung and lymph node sections are shown. 


\section{DISCUSSION}

The primary direction of research on MDA-9/ Syntenin (SDCBP) in cancer over the past two decades focused on defining its role in the context of tumor cells from different organ sites $(7-11,30,31,33,45,52,53)$ Although expression is significantly lower in normal vs. transformed cells, the MDA-9/Syntenin protein is ubiquitously expressed in the mouse (in both developing and adult stages $[28,51])$ and in adult human organs, e.g., skin, liver, gall bladder, colon (www. Proteinatlas.org). Tamura et al. first demonstrated that knockout of MDA-9 (syntenin-1; SDCBP) in mice was not embryonic lethal and mice that developed did not show obvious abnormalities when grown in pathogen-free conditions [28]. The $m d a-9^{-1}$ mouse model used in the present study was independently generated and characterized, corroborating the prior results that deletion of mda-9/syntenin in all tissues of the mouse is not lethal. In agreement with Tamura et al. [28], we also hypothesize that the lack of mda-9/syntenin in this animal is probably compensated by another variant of Syntenin, such as Syntenin-2, thereby preventing this knockout from being lethal.

MDA-9/Syntenin functions as a scaffold protein that interacts with a multitude of partner protein(s) and is involved in the generation or stabilization of active complexes, which play quintessential roles in multiple physiological activities $[52,53]$. In this way $m d a-9$ can elicit various effects depending on its location in a cell and its binding partners. As indicated, previous studies have focused primarily on the role of $m d a-9$ in cancer cells without defining the role of this molecule in normal tissue and the microenvironment. We hypothesized that lack of mda-9/syntenin expression might impact significantly

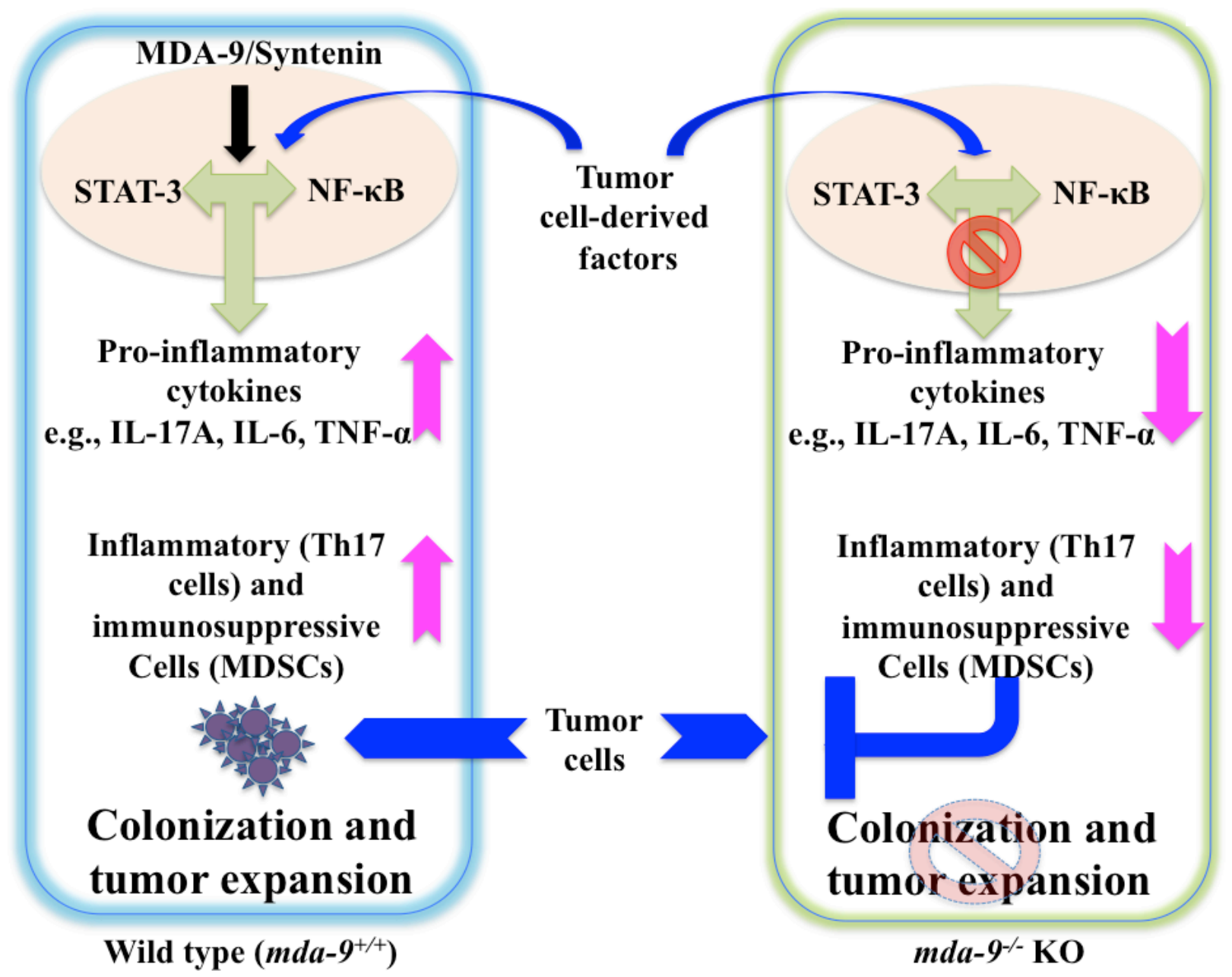

Figure 6: Model depicting the proposed role of host environmental mda-9/syntenin (SDCBP) expression in defining melanoma metastasis. Tumor cell-derived factor(s) may trigger an autocrine/paracrine loop resulting in the production of proinflammatory cytokine(s) in the microenvironment through STAT-3/NF- $\mathrm{kB}$ pathways. This positive loop and accumulation of proinflammatory cytokines then recruit inflammatory and immunosuppressive cells (e.g., Th17 cells and MDSCs) to support and facilitate tumor outgrowth. We hypothesize that MDA-9/Syntenin plays a critical role in this early induction phase of the metastatic process by promoting an inflammatory and immunosuppressive environment, possibly via the STAT-3/NF- $\mathrm{B}$ pathways. Absence of MDA-9/Syntenin negatively impacts on the inflammatory cascade and blocks the mobilization of inflammatory and immunosuppressive cells, which, as a consequence, leads to reduced tumor cell colonization and/or growth. 
only when cells were challenged with exogenous insults, such as those resulting from implantation or injection of tumor cells. To validate this hypothesis, we examined the tumorigenic/metastatic behavior of B16 cancer cells when placed in contact with mda-9/syntenin deficient tissue in an $m d a-9^{-/}$mouse. As predicted, tumor growth and metastasis was suppressed in $m d a-9^{-/}$mice as compared with WT animals. Migration and seeding of cancer cells in the lung after tail vein injection depends on the interactions of tumor cells and the resident host cells, i.e., the microenvironment [54]. Many studies have shown that the microenvironment has the capacity to eliminate, minimize or enhance tumorigenesis $[55,56]$ depending on its composition and the stromal cell proportions or their activation states $[34,57]$.

Our study reveals that ablation of mda-9/syntenin impairs tumor-promoting inflammation and tumorassociated immunosuppression, characterized by fewer inflammatory and immunosuppressive cells, e.g., MDSCs, Th17 in the lungs with metastases. Malignant progression is often associated with inflammation and immunosuppression in the tumor sites [58]. The potential tumor-promoting role of MDSCs has been well documented in studies involving multiple animal models (reviewed by Quail et al, [55, 59] and clinical samples [60]. Pro-inflammatory IL-17A-producing Th17 cells, are often associated with tumors (reviewed Guery et al,[61]) with both good and bad prognoses. The tumor-promoting mechanism of Th17 cells is dependent on the production of IL-17A, a pro-inflammatory cytokine, that is known to promote tumor angiogenesis $[62,63]$, stimulate tumor cells to produce IL-6 [43], and in some murine models recruit MDSCs within tumors [44]. Additionally, Th17 cells may also exert immunosuppressive functions via direct inhibition of tumor-specific $\mathrm{CD}^{+} \mathrm{T}$ effector cells [64], and development of IL- $17^{+}$Foxp $3^{+}$regulatory T cells [65]. The recruitment and expansion of various immune cells at least partially define the inflammatory status of the tumor microenvironment [66]. Although the precise mechanisms require further clarification, our results indicate that the basal levels of two major pro-inflammatory cytokines IL-6 and IL-17A are downregulated in the lungs from mda- $9^{-/}$mice. IL-17A is predominantly produced by immune cells, including $\mathrm{T}$ cells, macrophages, dendritic cells (DC), natural killer cells, natural killer T cells, and $\gamma \delta$-T cells [67]. Tissue resident cells such as fibroblasts also modulate the local inflammatory conditions by producing various cytokines and chemokines [57]. Although context dependent, STAT-3 activation has been reported to be involved in IL-17 regulation [68, 69]. Considering that we have previously shown that MDA-9/Syntenin can activate STAT-3 in cancer cells [33], we postulate that lack of $m d a-9 /$ syntenin in our $m d a-9^{--}$mice may abrogate STAT-3-mediated IL-17 production. Precisely how MDA9/Syntenin regulates IL-17 expression is currently an area of active investigation.
Although somewhat controversial, IL-17 is often considered to exert its' tumor-promoting effects in the context of inflammation [55]. More precisely, when IL17 is exogenously produced in the microenvironment, tumor growth is enhanced as documented in studies with $\mathrm{IL}-17^{-/-}$mice $[43,44,70]$ or intra-tumoral injection of IL-17 siRNA [71]. Using B16 cells, Wang et al [43] demonstrated that IL-17A induced IL-6 production by tumor cells, which in turn enhanced tumor growth in a STAT-3-dependent manner. Additionally, this study also revealed strong $\mathrm{CD}^{+} 8 \mathrm{~T}$ cell accumulation and IFN $-\gamma$ production in IL-17 $1 /$ mice. Our $m d a-9^{-/}$mouse model, which has a lower level of IL-17 mRNA compared to WT mice, also displayed reduced B16 tumor growth and lung metastases. It is possible that the lower expression of $I L$ 17 in $m d a-9^{-/}$mouse lungs impairs infiltration of MDSCs, an inflammatory cell population with immunosuppressive activity. Although we did not see complete regression of tumors (at the primary or metastatic sites), kinetics of tumor development and pathological state of tumorbearing lungs correlated with the accumulation of these inflammatory and immunosuppressive cells. Finally, our hypothesis that mda-9/syntenin expression in stroma is also important in tumor and metastatic development is validated in a spontaneous melanoma metastasis model. Additional studies will be needed to further understand the cross-talk of tumor cells (either expressing MDA-9/ Syntenin or not) within an mda-9/syntenin deficient tumor microenvironment, which will provide further insight into the multiple levels of involvement and functions of this gene in this complex process.

The present study is the first demonstration of the relevance of MDA-9/Syntenin expression in regulating inflammation and immunosuppression in the microenvironment thereby impacting tumor growth and metastasis. A schematic model of the role of MDA-9/ Syntenin in the tumor cell and microenvironment on metastasis is shown in Figure 6. Taking into account our previous research $(7-11,31,45,52,53)$ the present study also supports the newer concept that MDA-9/ Syntenin is a key protein product influencing metastasis by regulating both tumor cells and the microenvironment. Accordingly, this protein is an attractive therapeutic target for inhibiting metastasis. In principle, mda-9/syntenin could be targeted for inhibition genetically, using shRNA or siRNA delivered by nanoparticles or other approaches. For this strategy to be successful it would be necessary for the inhibitory RNAs to be delivered to metastatic cells in diverse and sometimes difficult to access regions of the body and to efficiently reduce expression to a level that would be therapeutically efficacious. Since a key mechanism by which MDA-9/Syntenin regulates cellular phenotypes is through protein-protein interactions through its PDZ domains, identifying small molecule inhibitors that specifically target the PDZ domains thereby disrupting the interactions and altering down stream signaling critical 
for activity would be of significant value. We are currently exploring both of these strategies to capitalize on the potential importance of mda-9/syntenin as a regulator of cancer invasion and metastasis in melanoma and other cancers. Finally, the $m d a-9^{--}$mouse models we have created will pave the way in comprehending the role of the microenvironment in the development and therapy of melanoma and potentially additional cancers.

\section{MATERIALS AND METHODS}

\section{Mouse model generation and breeding strategies}

\section{mda-9/syntenin knockout mice}

To investigate the physiological role of mda-9/ syntenin in metastasis development we generated a line of global mda-9/syntenin knockout mice ( $\left.m d a-9^{--}\right)$, starting with a line of $m d a-9$ "knockout first" mice ( $S d c b p^{\text {tmla(KOMP) }}$ Wtsi) obtained from the Knockout Mouse Project (KOMP) Repository [72], which were bred first to $\beta$-actin-FLPe mice (JAX stock \#005703) to generate the conditional knockout (CKO) allele in which exon 3 is floxed. These mice were then bred to EIIa-cre mice (JAX stock \#003724) to delete exon 3 , which results in a translational frameshift, leaving only 17 residues of the 299-residue MDA-9/ Syntenin protein. We confirmed the absence of MDA-9/ Syntenin protein in multiple tissues (lung shown) from mice homozygous for the knockout allele as well as the original "knockout first" allele, and retention of expression in mice with the floxed allele (Figure 1A).

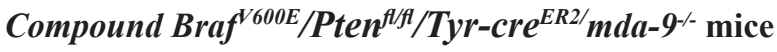

The BRaf ${ }^{V 600 E} /$ Pten $^{f l / f} /$ Tyr-cre ${ }^{E R 2}$ tamoxifen-inducible genetically engineered mouse model of metastatic melanoma (51) accurately recapitulates the full process of tumor initiation, progression and metastasis. This model was crossed with $m d a-9^{-/}$mice to develop BRaf ${ }^{V 600 E} / \mathrm{Pten}^{f /}$ $f /$ Tyr-cre ${ }^{E R 2} / m d a-9^{-/}$mice. Production of the $\mathrm{BRaf}^{V 600 E /}$

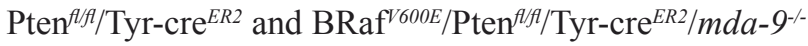
mice were particularly challenging because of the large number of genetically modified alleles being bred into each mouse. To facilitate efficient production of these mice, we generated sub-colonies of optimal breeders. For example, to generate $B R a f^{V 600 E} / P_{t e n}{ }^{f / f} / T y r-c r e^{E R 2}$ mice of the desired genotype (heterozygous for a modified Braf allele that expresses WT Braf until cre is expressed, and is then converted to the mutant BRaf ${ }^{V 600 E}$ allele; homozygous for a Pten floxed allele, and hemizygous for the Tyr-cre ${ }^{E R 2}$ transgene), we generated sub-colonies of: i) BRaf ${ }^{V 600 E /}$

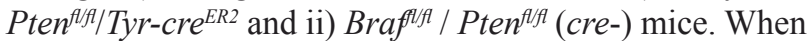
mice of these two genotypes were interbred, $50 \%$ of the offspring were of the experimental genotype, while the remaining $50 \%$ were cre- controls. Similarly, we also generated the following parental sub-colonies to develop

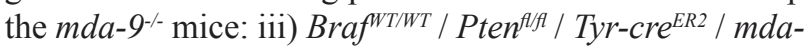
$9^{-/}$and iv) Brafllfl / Pten ${ }^{\text {Al/fl}} /$ mda-9-/ $($ cre-) mice.

\section{Western blotting analysis}

Freshly isolated organs (e.g., Lung) were minced with sterile scalpels and incubated with cell lysis buffer for 30 minutes on ice followed by homogenization using a glass homogenizer. All steps were performed on ice. Protein lysates were collected after centrifugation. For western blotting, we used MDA-9/syntenin (1:50, Cat. No. sc-100336) and $\beta$-actin (1:2000, Cat No. A-1978) antibodies from Santa Cruz Biotechnology ( Dallas, TX) and Sigma-Aldrich (St. Louis, MO), respectively.

\section{RNA extraction, cDNA preparation, and real-time PCR}

Total RNA was extracted from different mouse organs as indicated using QIAGEN miRNAeasy Mini Kit (QIAGEN). After confirming the quality of RNA, ABI cDNA Synthesis Kit (Applied Biosystems, Carlsbad, CA) was used to prepare cDNA. Real time PCR was performed using an ABI ViiA7 fast real-time PCR system and TaqMan gene expression assays according to the manufacturer's protocol. All relevant probes (mouse specific Taqman probe for IL-17A, IL-6, TNF- $\alpha$, GAPDH) were purchased from Applied Biosystems (Carlsbad, CA).

\section{Xenograft and experimental metastasis}

For xenograft experiments, 2 X $10^{5}$ B16 cells were subcutaneously injected in the right dorsal flank of mice as previously described [73]. Tumor volume was measured twice weekly with a caliper and calculated using formulas $\pi / 6 \times$ larger diameter $\times(\text { smaller diameter })^{2}$ [74] . Experimental lung metastasis was performed as previously described [73]. Briefly, B16 cells ( 1 X $10^{5}$ cells per mouse) suspended in $100 \mu \mathrm{L}$ PBS (without $\mathrm{Ca}^{2+}$ and $\mathrm{Mg}^{2+}$ ) were injected intravenously to generate pulmonary metastases. Based on the experimental design, mice were sacrificed at different time points.

\section{Routine pathological staining}

Tumors or organs were fixed in formalin. Samples were then embedded in paraffin, sectioned, and haematoxylin/eosin stained by the Virginia Commonwealth University Anatomic Pathology Laboratory. 


\section{Flow cytometry analysis}

Lungs from tumor-bearing mice were collected in cold RPMI and single cell suspensions were prepared as described previously $[73,75]$. Equal numbers of cells were re-suspended in FACS buffer (PBS containing 0.1\% BSA and $0.04 \%$ EDTA-Na $)$. After surface staining with the appropriate antibody [(e.g., for MDSCs, PE-CD11b ${ }^{+}$ (MI/70), PerCP/cy5.5-Ly6C (HK1.4) and APC-Ly6G (1A8); for Th17 cells, APC-CD4 (GK1.5) and PerCP/ Cy5.5-IL-17A (TC11-18H10.1)] as previously described (75), flow cytometry analysis was performed using a BD FACSCalibur flow cytometer. Data were analyzed using FlowJo software (Tree star, Ashland, OR). Antibodies were purchased from BioLegend (San Diego, CA).

\section{Statistical analysis}

Data are shown as the average \pm S.D. Unpaired twotailed Student $\mathrm{t}$-tests were conducted for calculating the " $p$ " value between two groups. A " $p$ " value $<0.05$ was considered statistically significant.

\section{ACKNOWLEDEGMENTS}

The present study was supported in part by the by NCI Cancer Center Support Grant to VCU Massey Cancer Center P30 CA016059 (P.B.F., D.S., J.J.W., X.Y.W.), VCU Massey Cancer Center developmental funds (P.B.F.), Human and Molecular Genetic Enhancement fund (S.K.D., P.B.F.), the VCU Institute of Molecular Medicine (VIMM) (P.B.F.), and the Samuel Waxman Cancer Research Foundation (SWCRF) (D.S., P.B.F.). Services in support of this project were provided by the VCU Massey Cancer Center Transgenic/Knock-out Mouse Facility and Flow Cytometry Core, supported in part with funding from NIH-NCI Cancer Center Support Grant P30 CA016059 (P.B.F., D.S., J.J.W., X.Y.W.). P.B.F. and D.S. are SWCRF Research Investigators. D.S. is the Harris Endowed Scholar in Cancer Research, X.Y.W. is the Mary Anderson Harrison Distinguished Professor in Cancer Research and P.B.F. holds the Thelma Newmeyer Corman Chair in Cancer Research. We thank Mohammad Al Zubi for his technical assistance in this project.

\section{CONFLICTS OF INTEREST}

The authors declare no conflict of interest.

\section{REFERENCES}

1. Chambers AF, Groom AC, MacDonald IC. Dissemination and growth of cancer cells in metastatic sites. Nature reviews Cancer. 2002;2(8):563-72.
2. Joyce JA, Pollard JW. Microenvironmental regulation of metastasis. Nature reviews Cancer. 2009;9(4):239-52.

3. Amend SR, Pienta KJ. Ecology meets cancer biology: the cancer swamp promotes the lethal cancer phenotype. Oncotarget. 2015;6(12):9669-78. doi: 10.18632/ oncotarget.3430.

4. Lin JJ, Jiang HP, Fisher PB. Characterization of a novel melanoma differentiation-associated gene, mda-9, that is down-regulated during terminal cell differentiation. Molecular and Cellular Differentiation. 1996;4(4):317-33.

5. Lin JJ, Jiang H, Fisher PB. Melanoma differentiation associated gene-9, mda-9, is a human gamma interferon responsive gene. Gene. 1998;207(2):105-10.

6. Grootjans JJ, Zimmermann P, Reekmans G, Smets A, Degeest G, Durr J, David G. Syntenin, a PDZ protein that binds syndecan cytoplasmic domains. Proceedings of the National Academy of Sciences of the United States of America. 1997;94(25):13683-8.

7. Boukerche H, Su ZZ, Kang DC, Fisher PB. Identification and cloning of genes displaying elevated expression as a consequence of metastatic progression in human melanoma cells by rapid subtraction hybridization. Gene. 2004;343(1):191-201.

8. Boukerche H, Su ZZ, Prevot C, Sarkar D, Fisher PB. mda-9/Syntenin promotes metastasis in human melanoma cells by activating c-Src. Proceedings of the National Academy of Sciences of the United States of America. 2008;105(41):15914-9.

9. Boukerche H, Aissaoui H, Prevost C, Hirbec H, Das SK, Su ZZ, Sarkar D, Fisher PB. Src kinase activation is mandatory for MDA-9/syntenin-mediated activation of nuclear factorkappaB. Oncogene. 2010;29(21):3054-66.

10. Das SK, Bhutia SK, Sokhi UK, Azab B, Su ZZ, Boukerche H, Anwar T, Moen EL, Chatterjee D, Pellecchia M, Sarkar D, Fisher PB. Raf kinase inhibitor RKIP inhibits MDA9/syntenin-mediated metastasis in melanoma. Cancer research. 2012; 72(23):6217-26.

11. Das SK, Bhutia SK, Azab B, Kegelman TP, Peachy L, Santhekadur PK, Dasgupta S, Dash R, Dent P, Grant S, Emdad L, Pellecchia M, Sarkar D, Fisher PB. MDA-9/ Syntenin and IGFBP-2 promote angiogenesis in human melanoma. Cancer research. 2013;73(2):844-54.

12. Baietti MF, Zhang Z, Mortier E, Melchior A, Degeest G, Geeraerts A, Ivarsson Y, Depoortere F, Coomans C, Vermeiren E, Zimmermann P, David G. Syndecansyntenin-ALIX regulates the biogenesis of exosomes. Nature cell biology. 2012;14(7):677-85.

13. Hurley JH, Odorizzi G. Get on the exosome bus with ALIX. Nature cell biology. 2012;14(7):654-5.

14. Xiao D, Ohlendorf J, Chen Y, Taylor DD, Rai SN, Waigel $\mathrm{S}$, Zacharias W, Hao H, McMasters KM. Identifying mRNA, microRNA and protein profiles of melanoma exosomes. Plos One. 2012;7(10):e46874.

15. Ju R, Zhuang ZW, Zhang JS, Lanahan AA, Kyriakides 
T, Sessa WC, Simons M. Angiopoietin-2 Secretion by Endothelial Cell Exosomes regulation by the phosphatidylinositol 3-kinase (pi3k)/akt/endothelial nitric oxide synthase (enos) and syndecan-4/syntenin pathways. Journal of Biological Chemistry. 2014;289(1):510-9.

16. Roucourt B, Meeussen S, Bao J, Zimmermann P, David G. Heparanase activates the syndecan-syntenin-ALIX exosome pathway. Cell research. 2015;25(4):412-28.

17. Pols MS, Klumperman J. Trafficking and function of the tetraspanin CD63. Experimental cell research. 2009;315(9):1584-92.

18. Beekman JM, Vervoort SJ, Dekkers F, van Vessem ME, Vendelbosch S, Brugulat-Panes A, van Loosdregt J, Braat AK, Coffer PJ. Syntenin-mediated regulation of Sox4 proteasomal degradation modulates transcriptional output. Oncogene. 2012;31(21):2668-79.

19. Xu NJ, Sun SY, Gibson JR, Henkemeyer M. A dual shaping mechanism for postsynaptic ephrin-B3 as a receptor that sculpts dendrites and synapses. Nature neuroscience. 2011;14(11):1421-U92.

20. Ro YT, Jang BK, Shin CY, Park EU, Kim CG, Yang SI. Akt regulates the expression of MafK, synaptotagmin I, and syntenin-1, which play roles in neuronal function. J Biomed science. 2010;17.

21. McClelland AC, Sheffler-Collins SI, Kayser MS, Dalva MB. Ephrin-B1 and ephrin-B2 mediate EphB-dependent presynaptic development via syntenin-1. Proceedings of the National Academy of Sciences of the United States of America. 2009;106(48):20487-92.

22. Sala-Valdes M, Gordon-Alonso M, Tejera E, Ibanez A, Cabrero JR, Ursa A, Mittelbrunn M, Lozano F, SanchezMadrid F, Yanez-Mo M. Association of syntenin-1 with M-RIP polarizes Rac-1 activation during chemotaxis and immune interactions. Journal of cell science. 2012;125(Pt 5):1235-46.

23. Chung JS, Cruz PD, Ariizumi K. Inhibition of T-cell activation by syndecan-4 is mediated by CD148 through protein tyrosine phosphatase activity. Eur J Immunol. 2011;41(6):1794-9.

24. Chen F, Du Y, Zhang Z, Chen G, Zhang M, Shu HB, Zhai Z, Chen D. Syntenin negatively regulates TRAF6-mediated IL-1R/TLR4 signaling. Cellular signalling. 2008;20(4):66674.

25. Gimferrer I, Ibanez A, Farnos M, Sarrias MR, Fenutria R, Rosello S, Zimmermann P, David G, Vives J, Serra-Pages C, Lozano F. The lymphocyte receptor CD6 interacts with syntenin-1, a scaffolding protein containing PDZ domains. Journal of immunology. 2005;175(3):1406-14.

26. Lazic D, Hufbauer M, Zigrino P, Buchholz S, Kazem S, Feltkamp MC, Mauch C, Steger G, Pfister H, Akgul B. Human papillomavirus type 8 E6 oncoprotein inhibits transcription of the PDZ protein syntenin-2. Journal of virology. 2012;86(15):7943-52.

27. Gordon-Alonso M, Rocha-Perugini V, Alvarez S, Moreno-
Gonzalo O, Ursa A, Lopez-Martin S, Izquierdo-Useros N, Martinez-Picado J, Munoz-Fernandez MA, Yanez-Mo M, Sanchez-Madrid F. The PDZ-adaptor protein syntenin-1 regulates HIV-1 entry. Molecular biology of the cell. 2012;23(12):2253-63.

28. Tamura K, Ikutani M, Yoshida T, Tanaka-Hayashi A, Yanagibashi T, Inoue R, Nagai Y, Adachi Y, Miyawaki T, Takatsu K, Mori H. Increased production of intestinal immunoglobulins in Syntenin-1-deficient mice. Immunobiology. 2015;220(5):597-604.

29. Hwangbo C, Park J, Lee JH. mda-9/Syntenin protein positively regulates the activation of Akt protein by facilitating integrin-linked kinase adaptor function during adhesion to type I collagen. The Journal of biological chemistry. 2011;286(38):33601-12.

30. Hwangbo C, Kim J, Lee JJ, Lee JH. Activation of the integrin effector kinase focal adhesion kinase in cancer cells is regulated by crosstalk between protein kinase Calpha and the PDZ adapter protein mda-9/syntenin. Cancer research. 2010;70(4):1645-55.

31. Dasgupta S, Menezes ME, Das SK, Emdad L, Janjic A, Bhatia S, Mukhopadhyay ND, Shao C, Sarkar D, Fisher PB. Novel role of MDA-9/syntenin in regulating urothelial cell proliferation by modulating EGFR signaling. Clinical cancer research. 2013;19(17):4621-33.

32. Gangemi R, Mirisola V, Barisione G, Fabbi M, Brizzolara A, Lanza F, Mosci C, Salvi S, Gualco M, Truini M, Angelini G, Boccardo S, Cilli M, Airoldi I, Queirolo P, Jager MJ, Daga A, Pfeffer U, Ferrini S. Mda-9/Syntenin is expressed in uveal melanoma and correlates with metastatic progression. Plos One. 2012;7(1), e29989.

33. Oyesanya RA, Bhatia S, Menezes ME, Dumur CI, Singh KP, Bae S, Troyer DA, Wells RB, Sauter ER, Sidransky D, Fisher PB, Semmes OJ, Dasgupta S. MDA-9/Syntenin regulates differentiation and angiogenesis programs in head and neck squamous cell carcinoma. Oncoscience. 2014;1(11):725-37. doi: 10.18632/oncoscience.99.

34. Hanahan D, Weinberg RA. Hallmarks of cancer: the next generation. Cell. 2011;144(5):646-74.

35. Rutkowski MR, Svoronos N, Perales-Puchalt A, ConejoGarcia JR. The tumor microenvironment: cancerpromoting networks beyond tumor beds. Advances cancer research.2015;128235:235-262.

36. Peske JD, Woods AB, Engelhard VH. Control of CD8 T-Cell Infiltration into Tumors by vasculature and microenvironment. Immunotherapy of cancer. 2015;128:263-307.

37. Gabrilovich DI, Nagaraj S. Myeloid-derived suppressor cells as regulators of the immune system. Nature reviews immunology. 2009;9(3):162-74.

38. Ostrand-Rosenberg S, Sinha P. Myeloid-derived suppressor cells: linking inflammation and cancer. Journal of immunology. 2009;182(8):4499-506.

39. Parker KH, Beury DW, Ostrand-Rosenberg S. Myeloid- 
Derived suppressor cells: Critical cells driving immune suppression in the tumor microenvironment. Immunotherapy of cancer. 2015;128:95-139.

40. Huang B, Pan PY, Li QS, Sato AI, Levy DE, Bromberg J, Divino CM, Chen SH. Gr-1(+)CD115(+) immature myeloid suppressor cells mediate the development of tumor-induced $\mathrm{T}$ regulatory cells and T-cell anergy in tumor-bearing host. Cancer research. 2006;66(2):1123-31.

41. Hanson EM, Clements VK, Sinha P, Ilkovitch D, OstrandRosenberg S. Myeloid-derived suppressor cells downregulate L-selectin expression on CD4+ and CD8+ T cells. Journal of immunology. 2009;183(2):937-44.

42. Zou W. Immunosuppressive networks in the tumour environment and their therapeutic relevance. Nature reviews cancer. 2005;5(4):263-74.

43. Wang L, Yi TS, Kortylewski M, Pardoll DM, Zeng DF, $\mathrm{Yu}$ H. IL-17 can promote tumor growth through an IL-6Stat3 signaling pathway. Journal of experimental medicine. 2009;206(7):1457-64.

44. He DG, Li H, Yusuf N, Elmets CA, Li J, Mountz JD, Xu H. IL-17 Promotes tumor development through the induction of tumor promoting microenvironments at tumor sites and myeloid-derived suppressor cells. Journal of immunology. 2010;184(5):2281-8.

45. Boukerche H, Su ZZ, Emdad L, Baril P, Balme B, Thomas L, Randolph A, Valerie K, Sarkar D, Fisher PB. mda-9/ Syntenin: a positive regulator of melanoma metastasis. Cancer research. 2005;65(23):10901-11.

46. Rondepierre F, Bouchon B, Bonnet M, Moins N, Chezal JM, D'Incan M, Degoul F. B16 melanoma secretomes and in vitro invasiveness: syntenin as an invasion modulator. Melanoma research. 2010;20(2):77-84.

47. Damsky WE, Rosenbaum LE, Bosenberg M. Decoding melanoma metastasis. Cancers. 2010;3(1):126-63.

48. Qiu HM, Orr FW, Jensen D, Wang HH, McIntosh AR, Hasinoff BB, Nance DM, Pylypas S, Qi K, Song C, Muschel RJ, Al-Mehdi AB. Arrest of B16 melanoma cells in the mouse pulmonary microcirculation induces endothelial nitric oxide synthase-dependent nitric oxide release that is cytotoxic to the tumor cells. American Journal of Pathology. 2003;162(2):403-12.

49. Filipazzi P, Valenti R, Huber V, Pilla L, Canese P, Iero M, Castelli C, Mariani L, Parmiani G, Rivoltini L. Identification of a new subset of myeloid suppressor cells in peripheral blood of melanoma patients with modulation by a granulocyte-macrophage colony-stimulation factor-based antitumor vaccine. Journal of clinical oncology : official journal of the American Society of Clinical Oncology. 2007;25(18):2546-53.

50. Dankort DPC, Cartlidge RA, Nelson B, Karnezis AN, Damsky WE, Jr., You MJ, DePinho RA, McMahon M, Bosenberg M. BRafV600E cooperates with Pten silencing to elicit metastatic melanoma. Nat Genet. 2009:Published in final edited form as: Nature Genetics. 2009 May; 41(5): 544-552.

51. Jeon HY, Das SK, Dasgupta S, Emdad L, Sarkar D, Kim SH, Lee SG, Fisher PB. Expression patterns of MDA-9/ syntenin during development of the mouse embryo. Journal of molecular histology. 2013;44(2):159-66.

52. Kegelman TP, Das SK, Emdad L, Hu B, Menezes ME, Bhoopathi P, Wang XY, Pellecchia M, Sarkar D, Fisher PB. Targeting tumor invasion: the roles of MDA-9/Syntenin. Expert opinion on therapeutic targets. 2015;19(1):97-112.

53. Das SK, Bhutia SK, Kegelman TP, Peachy L, Oyesanya RA, Dasgupta S, Sokhi UK, Azab B, Dash R, Quinn BA, Kim K, Barral PM, Su ZZ, Boukerche H, Sarkar D, Fisher PB. MDA-9/syntenin: a positive gatekeeper of melanoma metastasis. Frontiers in bioscience : a journal and virtual library. 2012;17:1-15.

54. Grivennikov SI, Greten FR, Karin M. Immunity, inflammation, and cancer. Cell. 2010;140(6):883-99.

55. Quail DF, Joyce JA. Microenvironmental regulation of tumor progression and metastasis. Nature medicine. 2013;19(11):1423-37.

56. Wang XY, Fisher PB. Immunotherapy of Cancer Preface. Immunotherapy of Cancer. Edited by Wang XY and Fisher PB. Advances in Cancer Research. 2015;128:1-375.

57. Hanahan D, Coussens LM. Accessories to the crime: functions of cells recruited to the tumor microenvironment. Cancer cell. 2012;21(3):309-22.

58. Whiteside TL. Immune suppression in cancer: effects on immune cells, mechanisms and future therapeutic intervention. Seminars in cancer biology. 2006;16(1):3-15.

59. Talmadge JE, Gabrilovich DI. History of myeloid-derived suppressor cells. Nature reviews Cancer. 2013;13(10):73952.

60. Diaz-Montero CM, Salem ML, Nishimura MI, GarrettMayer E, Cole DJ, Montero AJ. Increased circulating myeloid-derived suppressor cells correlate with clinical cancer stage, metastatic tumor burden, and doxorubicincyclophosphamide chemotherapy. Cancer immunology, immunotherapy. 2009;58(1):49-59.

61. Guery L and Hugues S. Th17 Cell Plasticity and Functions in Cancer Immunity. BioMed research international. 2015; 2015:314620.

62. Numasaki M, Fukushi J, Ono M, Narula SK, Zavodny PJ, Kudo T, Robbins PD, Tahara H, Lotze MT. Interleukin-17 promotes angiogenesis and tumor growth. Blood. 2003;101(7):2620-7.

63. Numasaki M, Watanabe M, Suzuki T, Takahashi H, Nakamura A, McAllister F, Hishinuma T, Goto J, Lotze MT, Kolls JK, Sasaki H. IL-17 enhances the net angiogenic activity and in vivo growth of human non-small cell lung cancer in SCID mice through promoting CXCR2-dependent angiogenesis. Journal of immunology. 2005;175(9):6177-89. 
64. Liu JK, Duan YZ, Cheng XM, Chen X, Xie W, Long HX, Lin ZH, Zhu B. IL-17 is associated with poor prognosis and promotes angiogenesis via stimulating VEGF production of cancer cells in colorectal carcinoma. Biochemical and biophysical research communications. 2011;407(2):348-54.

65. Du RJ, Zhao H, Yan F, Li H. IL-17(+)Foxp3(+) T cells: an intermediate differentiation stage between Th17 cells and regulatory T cells. J Leukocyte Biol. 2014;96(1):39-48.

66. Luster $\mathrm{AD}$, Alon $\mathrm{R}$, von Andrian UH. Immune cell migration in inflammation: present and future therapeutic targets. Nature immunology. 2005;6(12):1182-90.

67. Korn T, Bettelli E, Oukka M, Kuchroo VK. IL-17 and Th17 Cells. Annual review of immunology. 2009;27:485-517.

68. Chen Z, Laurence A, Kanno Y, Pacher-Zavisin M, Zhu BM, Tato C, Yoshimura A, Hennighausen L, O'Shea JJ. Selective regulatory function of Socs 3 in the formation of IL-17-secreting T cells. Proceedings of the National Academy of Sciences of the United States of America. 2006;103(21):8137-42.

69. Nishihara M Ogura H, Ueda N, Tsuruoka M, Kitabayashi C, Tsuji F, Aono H, Ishihara K, Huseby E, Betz UA, Murakami M, Hirano T. IL-6-gp130-STAT3 in T cells directs the development of IL-17+ Th with a minimum effect on that of Treg in the steady state. International Immunology 2007 Jun;19(6):695-702 .

70. Carmi Y, Rinott G, Dotan S, Elkabets M, Rider P, Voronov E, Apte RN. Microenvironment-derived IL-1 and IL17 interact in the control of lung metastasis. Journal of immunology. 2011;186(6):3462-71.
71. Hayata K, Iwahashi M, Ojima T, Katsuda M, Iida T, Nakamori M, Ueda K, Nakamura M, Miyazawa M, Tsuji T, Yamaue H. Inhibition of IL-17A in tumor microenvironment augments cytotoxicity of tumorinfiltrating lymphocytes in tumor-bearing mice. Plos One. 2013;8(1):e53131.

72. Lloyd KC. A knockout mouse resource for the biomedical research community. Annals of the New York Academy of Sciences. 2011;1245:24-6.

73. Yu XF, Guo CQ, Yi HF, Qian J, Fisher PB, Subjeck JR, Wang XY. A Multifunctional Chimeric Chaperone Serves as a Novel Immune Modulator Inducing Therapeutic Antitumor Immunity. Cancer research. 2013;73(7):2093103.

74. Sarkar D, Su ZZ, Vozhilla N, Park ES, Randolph A, Valerie K, Fisher PB. Targeted virus replication plus immunotherapy eradicates primary and distant pancreatic tumors in nude mice. Cancer research. 2005;65(19):905663.

75. Yi HF, Guo CQ, Yu XF, Zuo DM, Wang XY. Mouse CD11b(+)Gr-1(+) Myeloid Cells Can Promote Th17 Cell Differentiation and Experimental Autoimmune Encephalomyelitis. Journal of immunology. 2012;189(9):4295-304. 